\title{
A conceptual analysis of conceptual analysis in analytic jurisprudence
}

Article

Accepted Version

Zanghellini, A. (2017) A conceptual analysis of conceptual analysis in analytic jurisprudence. Canadian Journal of Law and Jurisprudence, 30 (2). pp. 467-491. ISSN 2056-4260 doi: https://doi.org/10.1017/cjlj.2017.21 Available at https://centaur.reading.ac.uk/69083/

It is advisable to refer to the publisher's version if you intend to cite from the work. See Guidance on citing.

To link to this article DOI: http://dx.doi.org/10.1017/cjlj.2017.21

Publisher: Cambridge University Press

All outputs in CentAUR are protected by Intellectual Property Rights law, including copyright law. Copyright and IPR is retained by the creators or other copyright holders. Terms and conditions for use of this material are defined in the End User Agreement.

\section{www.reading.ac.uk/centaur}

\section{CentAUR}

Central Archive at the University of Reading

Reading's research outputs online 


\section{A CONCEPTUAL ANALYSIS OF CONCEPTUAL ANALYSIS IN ANALYTIC JURISPRUDENCE}

Aleardo Zanghellini

\section{Introduction}

The principal methodological debate in contemporary legal philosophy concerns whether it is possible for legal philosophers to provide non-evaluative accounts of law. ${ }^{1}$ There is widespread consensus on the inescapability of making evaluative judgements in relation to the economy, clarity, explanatory power, etc., of one's account, ${ }^{2}$ as well as 'in trying to sort out what is central and significant in the common understanding of the concept of law' ${ }^{3}$ But it is controversial whether evaluative judgements of the moral variety specifically must play a role in a philosophical account of what law is - a claim denied by methodological positivists ${ }^{4}$ and affirmed by methodological anti-positivists. ${ }^{5}$ My goal in this article is not to add to this, a well-rehearsed, debate. ${ }^{6}$ Rather, I address a question sometimes treated as incidental to it namely, what conceptual analysis is, as the explicit or implicit methodology of much contemporary mainstream legal philosophy.

The last fifteen years have seen significant contributions addressing the nature of conceptual analysis in legal theory, filling a vacuum that had been lamented by some legal scholars; ${ }^{7}$ but this work has raised as many questions as it has answered. What is conceptual analysis? Are there different kinds of it? Why is it the methodology of much mainstream legal philosophy? Does it have to be? Does conceptual analysis yield all the knowledge there is to have about law? Does it have anything or much to do with linguistic analysis and with the meaning of words? Does it have to do with anything other than linguistic analysis and the meaning

\footnotetext{
${ }^{1}$ See eg Julie Dickson, Evaluation and Legal Theory (Hart 2011); Brian Leiter, 'Beyond the Hart/Dworkin Debate: The Methodology Problem in Jurisprudence' (2003) 48 American Journal of Jurisprudence 17, 30ff; Veronica Rodriguez Blanco, 'The Methodological Problem in Legal Theory: Normative and Descriptive Jurisprudence Revisited' (2006) 19 Ratio Juris 26.

2 Julie Dickson, 'Methodology in Jurisprudence: A Critical Survey' (2004) 10 Legal Theory 117, 125, 135; Leiter, 'Beyond the Hart/Dworkin Debate' (n 1), 34-35.

${ }^{3}$ Joseph Raz, Ethics in the Public Domain (Oxford University Press 1995) 237. See Dickson, 'Methodology in Jurisprudence' (n 2), 119-120, 122-123, 125-129, 132-133, 140; Leiter, 'Beyond the Hart/Dworkin Debate' (n 1), 4043; Nicola Lacey, 'Analytical Jurisprudence versus Descriptive Sociology Revisited' (2006) 84 Texas Law Review 945, 955.

${ }^{4}$ See eg Dickson, Evaluation and Legal Theory (n 1); Joseph Raz, 'Two Views on the Nature of Law: A Partial Comparison' in Jules L Coleman (ed), Hart's Postscript: Essays on the Postscript to 'The Concept of Law' (Oxford University Press 2001) 2, 21; Jules L Coleman, The Practice of Principle: In Defence of a Pragmatist Approach to Legal Theory (Oxford University Press 2003), 175-207.

${ }^{5}$ See eg Ronald Dworkin, 'Hart's Postscript and the Character of Political Philosophy' (2004) 24 Oxford Journal of Legal Studies 1; John Finnis, Natural Law and Natural Rights ( $2^{\text {nd }}$ edn, Oxford University Press 2011) 3-18; Stephen R Perry, 'Hart's Methodological Positivism' in Jules L Coleman (ed), Hart's Postscript: Essays on the Postscript to 'The Concept of Law' (Oxford University Press 2001), 311; TRS Allan, The Sovereignty of Law: Freedom, Constitution and Common Law (Oxford University Press 2013); Stuart Lakin, 'Defending and Contesting the Sovereignty of Law: The Public Lawyer as Interpretivist' (2015) 78 Modern Law Review 549.

${ }^{6}$ Suffice to say that, if methodological anti-positivism is sound, I think it must be for reasons such as those adduced by Finnis rather than Dworkin, which I incline to reject on grounds best stated in Raz, 'Two Views on the Nature of Law' (n 4), 11-37, as well as David Plunkett and Timothy Sundell, 'Dworkin's Interpretivism and the Pragmatics of Legal Disputes' (2013) 19 Legal Theory 242.

${ }^{7}$ Brian Bix, 'Conceptual Questions and Jurisprudence' (1995) 1 Legal Theory 465; Brian Leiter, 'Legal Realism, Hard Positivism, and the Limits of Conceptual Analysis' in Jules L Coleman (ed), Hart's Postscript: Essays on the Postscript to 'The Concept of Law' (Oxford University Press 2001) 355, 357.
} 
of words? Is it justifiable to critique it as armchair theorising? I maintain that these and other questions can be more clearly and satisfactorily addressed if we appreciate: a) that there is a central case of conceptual analysis; b) the ways in which non-paradigmatic cases differ from the central one.

My use, in this article, of the 'central case' analytical device is heuristic. There is disagreement about the criteria to be used to identify central cases from non-central cases of any particular kind - a disagreement that maps onto the broader debate (which, as mentioned, I will not enter into) about whether jurisprudential explanations must be predicated on morally evaluative judgements. ${ }^{8}$ My claim - which I hope the article as a whole vindicates - is simply that it significantly assists our understanding of conceptual analysis to single out its central case in the way I will do, and I will state clearly the criteria in light of which I take the central case to be central. ${ }^{9}$

Though associated primarily with Finnis, the 'central case' device is regularly employed in analytic jurisprudence. ${ }^{10}$ In the next section I will argue that the central (or paradigmatic) case of conceptual analysis can be usefully identified with Ayer's characterisation of the task of philosophical practice. I do not rule out that identifying its central case differently may also contribute to elucidating the concept of conceptual analysis. ${ }^{11}$ Furthermore, on my rendition of it, the central case is, as we will see, neither statistically typical, nor the methodologically most desirable way of carrying out conceptual analysis (if only because of its artificiality). ${ }^{12}$ Likewise, the non-central cases are not perverted or deficient versions of conceptual analysis though they are less pure than the central case, in a sense that will become clear.

The article defends the following statements. The central case of conceptual analysis involves the clarification of the meaning of terms used to express particular concepts. I shall call these terms, following Endicott, 'concept-words'. ${ }^{13}$ Concept-words that legal philosophers interrogate include not only 'law', 'rights' and 'adjudication', but also discipline-specific ones, such as 'promise' and 'reliance' in contract law. There are no fixed rules about what legal terms count as concept-words worthy of legal philosophical analysis; for intuitive reasons, however, legal philosophers tend to focus on those that are possessed of a degree of internal complexity and even contestation. The important point is that the central case of conceptual analysis aims at yielding analytic truths - that is truths by virtue of meaning alone, ascertained on the basis of intuitions about linguistic conventions governing the use of concept-words. Much contemporary conceptual analysis, however, differs from the central case: it does not seek to yield analytic truths; it aspires to inform us both about our use of words and about the world to which the words apply; it is revisionist of linguistic conventions; it is not always a priori, requiring philosophers to reach beyond their linguistic competence and take into account their own experiential knowledge or empirical information in order to clarify the meaning of concepts.

There is more to law and the legal world than what conceptual analysis can reveal. Empirical social science has much to say about the legal world, but subordinating conceptual analysis to the concerns or methods of empirical social science is a mistake: it entails the loss of the distinctive kind of legal knowledge that only something like conceptual analysis can contribute. The broadest sense of 'conceptual analysis' sees the analytic philosopher in the business of directly speculating about objects and properties in the world not for the sake of clarifying the concepts that apply to them, but to explain the nature of these objects and properties. In respect of this last sense of 'conceptual analysis', the criticism of conceptual analysis's socalled 'armchair' character is sometimes justified.

\footnotetext{
${ }^{8}$ Finnis (n 5), 11-18.

${ }^{9}$ See text between note 36 and the new heading.

${ }^{10}$ Finnis (n 5), 9-18.

${ }^{11}$ See text to notes 70-71 and 95-96 (drawing attention to Raz's remarks to the effect that conceptual accounts are always incomplete and context-dependent).

${ }^{12}$ See text to note 91.

${ }^{13}$ Timothy A O Endicott, 'Herbert Hart and the Semantic Sting' in Jules L Coleman (ed), Hart's Postscript: Essays on the Postscript to 'The Concept of Law' (Oxford University Press 2001) 40, 44.
} 


\section{The Central Case of Conceptual Analysis}

When I say that conceptual analysis is the methodology of much 'contemporary mainstream legal philosophy', I mean the kind of legal theory inaugurated by Hart, associated primarily with Oxford, and from which critical legal theory takes its distance. Hart placed his own enterprise within the tradition of analytic philosophy ${ }^{14}$ and the label can be loosely applied to all mainstream legal philosophy.

Analytic philosophy, in its early form, can be seen as a reaction to philosophical knowledge that analytic philosophers deemed to lack modesty and rigour. In terms of modesty, in the first half of the twentieth century analytic philosophy was associated with a distrust in the ability of certain traditional philosophical domains, such as ethics or metaphysics, to generate reliable knowledge - indeed, to say anything meaningful at all. ${ }^{15}$ Philosophers, according to analytic philosophers, should lower their ambitions and philosophize only about those domains which were amenable to philosophical investigation. ${ }^{16}$ In terms of rigour, analytic philosophers sometimes expressed dissatisfaction with the obscure character of traditional philosophy, ${ }^{17}$ but the main target of critique was its reliance on purely speculative cognition. ${ }^{18}$ As Ayer put it:

[T] he philosopher ... must not attempt to formulate speculative truths, or to look for first principles, or to make a priori judgements about the validity of our empirical beliefs. He must, in fact, confine himself to works of clarification and analysis ... the activity of philosophizing is essentially analytic ${ }^{19}$

The sort of 'clarification and analysis' that Ayer had in mind is just the central case of conceptual analysis. To understand what it is and why analytic philosophers believed it to provide a methodology that did not suffer from the defects they associated with traditional speculative philosophy, we must investigate the relationship between (early) analytic philosophy and the philosophy of language.

The indebtedness of Hart's analytic jurisprudence to modern philosophy of language ${ }^{20}$ reflects the intimate relationship between the latter and all analytic philosophy. It is not just that the philosophy of language is one branch of analytic philosophy; rather, the analytic philosophical tradition, as it developed over the course of the twentieth century, is rooted in the philosophy of language. First, the philosophy of language - especially its use of formal notation to expose and examine the logical structure of statements can be seen as setting the standard of objectivity and precision to which all analytic philosophy aspires. Secondly, to the extent that analytic philosophy privileges conceptual analysis,${ }^{21}$ it more or less inevitably implicates itself in the philosophy of language.

Marmor clarifies the relationship between conceptual analysis and the analysis of language: 'When we try to elucidate or analyze a concept, [we are] figuring out what the word, in its relevant settings, means

\footnotetext{
${ }^{14}$ HLA Hart, The Concept of Law (Clarendon Press 1961) v.

${ }^{15}$ Alfred Jules Ayer, Language, Truth and Logic (Penguin 1971) ch 1, ch 6.

${ }^{16}$ Bertrand Russell, A History of Western Philosophy (Allen and Unwin 1946) 862-864.

${ }^{17}$ Russell (n 16) 757, 761.

18 Ayer (n 15) 33.

${ }^{19}$ Ayer (n 15) 36-37.

${ }^{20}$ Nicos Stravropoulos, 'Hart's Semantics' in Jules L Coleman (ed), Hart's Postscript: Essays on the Postscript to 'The Concept of Law' (Oxford University Press 2001) 59, 60. Analytic jurisprudence has particular affinities with ordinary language philosophy. Brian Leiter and Alex Langlinais, 'The Methodology of Legal Philosophy' (University of Chicago Public Law \& Legal Theory Working Paper No. 407, 2012) 5; Brian Leiter, 'On the Demarcation Problem in Jurisprudence: New Case for Skepticism’ (2011) 31 Oxford Journal of Legal Studies 663, 666.

${ }^{21}$ Hilary Kornblith, 'Is there Room for Armchair theorising in Epistemology?' in Matthew C Haug (ed), Philosophical Methodology: The Armchair or the Laboratory (Routledge 2014) 195, 203.
} 
in the language in question. ${ }^{22}$ But the branch of philosophy that systematically investigates (the ways in which any given ' $\mathrm{X}$ ' conveys) meaning is precisely the philosophy of language. In studying how language works, philosophers of language have concerned themselves with developing theories of meaning: they have tried to explain how terms and utterances convey meaning, under what circumstances an utterance conveys something true, how the meaning of different terms relate to objects in the world, etc. Analytic philosophy's (including analytic jurisprudence's) debt to the philosophy of language is then a function of the fact that analytic philosophy's distinctive approach (conceptual analysis) puts the emphasis on questions of meaning, in conjunction with the fact that it is precisely philosophers of language who have prioritized developing theories of meaning.

Ayer's remarks bear out the centrality of linguistic analysis to early (pre-World War II) analytic philosophy:

[T] he philosopher, as an analyst, is not directly concerned with the physical properties of things. He is concerned only with the way in which we speak about them. ... [T] he propositions of philosophy are ... linguistic in character - that is, they do not describe the behaviour of physical, or even mental, objects; they express definitions ... [P] hilosophy is a department of logic. ... it is concerned with the formal consequences of our definitions and not with questions of empirical fact. ... [P]hilosophy does not in any way compete with science. ${ }^{23}$

The attraction of conceptual analysis for early analytic philosophy was the promise it held out to its practitioners that they might be able to come up with something as crisp as an analytic truth: something whose truth value is only dependent on objective linguistic conventions and the principles of logic. While synthetic truths are statements whose truths is proved a posteriori through empirical observation (eg, 'There are as many women as men in Trudeau's cabinet'), analytic truths are a priori: they are statements that are true by virtue of meaning alone (eg, 'Cabinet is a collective body'). ${ }^{24}$

Ayer argued that analytic propositions are irrefutable through a posteriori methods because they 'simply record our determination to use words in a certain fashion' without making 'any assertion about the empirical world'. ${ }^{25}$ They are also necessary because in order to deny them, we would have to repudiate the validity of the very linguistic conventions that we would be using in trying to deny them, thus committing ourselves to self-contradiction. ${ }^{26}$ Conversely, until the second half of the twentieth century, synthetic truths were regarded as always contingent, ${ }^{27}$ on the ground that 'it is always conceivable that a future experience will lead us to abandon them'. ${ }^{28}$ Thus, the sentence 'All humans are mortal' ordinarily expresses a contingent synthetic generalisation always open to refutation. The only thing that may be necessary in that sentence is the analytic truth that the concept of mortal is contained within that of human; that is, that we have fixed the concept of mortality as one of the defining features of the concept of human. If our linguistic conventions in fact make these conceptual moves, then it is an analytic and necessary truth that 'all humans are mortal', although empirically it may one day prove not to be true that all humans die. ${ }^{29}$

\footnotetext{
22 Andrei Marmor, 'Farewell to Conceptual Analysis (in Jurisprudence)' in Wil Waluchow and Stefan Sciaraffa (eds), Philosophical Foundations of the Nature of Law (Oxford University Press 2013) 209, 211.

${ }^{23}$ Ayer (n 15) 44.

${ }^{24}$ The distinction originates with Kant and was refined by Ayer, according to whom 'we say that a proposition is analytic when its validity depends solely on the definitions of the symbols it contains, and synthetic when its validity is determined by the facts of experience.' Ayer (n 15) 73.

${ }^{25}$ Ayer (n 15) 80.

${ }^{26}$ Ayer (n 15) 80.

${ }^{27}$ Scott Soames, Philosophy of Language (Princeton University Press 2010) 77.

${ }^{28}$ Ayer (n 15) 96.

${ }^{29}$ Ayer (n 15) 95-96. ' [I]f experience leads us to entertain a very strong belief that everything of the kind A has the property of being a $\mathrm{B}$, we tend to make the possession of this property a defining characteristic of the kind. Ultimately
} 
Pre-World War II analytic philosophers, thus, focused on analytic truths established a priori, because they were the only truths that they regarded as both worthy of philosophical investigation (on account of their necessity) and capable of such investigation (working out their conditions did not require speculation on metaphysical properties but an analysis of linguistic conventions and the ways in which they determine meaning). Thus, the sense in which analytic philosophy, as envisaged by Ayer, was 'analytic' is that it aspired to generate analytic statements (ones that are true by virtue of meaning alone) in response to 'What does ' $X$ " mean?'-type questions. Ayer maintained that analytic propositions 'give us new knowledge' by calling 'attention to linguistic usages, of which we might otherwise not be conscious' and by revealing 'unsuspected implications in our assertions and beliefs'; but he also argued that in a sense they 'add nothing to our knowledge', for after all they only inform us on the linguistic conventions we already share. ${ }^{30}$

For Ayer, then, analytic philosophy is primarily ${ }^{31}$ a matter of providing definitions, whose validity 'depends solely on their compatibility with [the] conventions' of the language 'from which [the] definitions are deduced' ${ }^{32}$ The method in which analytic philosophers identify the meaning of any given concept-word ' $X$ ' then, involves relying on their own intuitions about our use of language, and particularly their competence in the linguistic conventions that fix the meaning of ' $X$ '. Suppose now that relevant linguistic conventions fix $\mathrm{Z}$ as the meaning of ' $\mathrm{X}$ '. If the analytic philosopher's answer to the question 'What does "X" mean?' takes the form of " $X "$ " = Z', this will be an analytic truth. For Ayer, however, providing simple synonymous definitions (such as 'oculist = eye doctor') is the job of dictionaries rather than philosophy, which is instead after more complex definitions (or something approximating them). ${ }^{33}$ These definitions which he calls 'definitions in use' - proceed 'not by saying that [a symbol] is synonymous with some other symbol, but by showing how the sentences in which it significantly occurs can be translated into equivalent sentences, which contain neither the definiendum itself, nor any of its synonyms. ${ }^{34}$ Raz's definition of 'right' (as a noun) is a good example: ${ }^{35}$ it translates the sentence 'A has a right' into the sentence that 'A's interest is of sufficient importance to ground duties in others.'

In short, traditional analytic philosophy aimed at yielding analytic truths, and justified itself on the ground that delivering purely analytic, (tauto)logical, necessary truths was the only legitimate task for philosophy. The language-based method through which pre-World War II analytic philosophy saw itself as performing this task is the central case of conceptual analysis, ${ }^{36}$ even if Ayer did not himself use the expression 'conceptual analysis' to characterize it. It is useful to think of the kind of conceptual analysis embedded in this philosophical practice as the central case of conceptual analysis for the following reasons: it is (or aspires to be) a pure form of conceptual analysis, that is, one that does not rely on a posteriori methods at all; historically, it was in this pure form that conceptual analysis was expressly articulated as the distinctive method of analytic philosophy; and it is through an appreciation of this method that we can make sense of the expressions 'analytic philosophy', 'analytic truths' and 'conceptual analysis' in a way that establishes full coherence among them. The closer one's philosophical practice manages to get to yielding the sort of definitions discussed in this section, the more analytic - in the classical sense of 'analytic'

we may refuse to call anything A unless it is also a B. And in that case the sentence 'All A's are B's' which originally expressed a synthetic generalization, would come to express a plain [analytic truth]' (95).

${ }^{30}$ Ayer (n 15) 74.

${ }^{31}$ Ayer later qualified his view that philosophy is exclusively a matter of providing definitions. Ayer (n 15) 196.

${ }^{32}$ Ayer (n 15) 62.

${ }^{33}$ Ayer (n 15) 196.

${ }^{34}$ Ayer (n 15) 49.

35 Joseph Raz, 'On the Nature of Rights' (1984) 93 Mind 194.

${ }^{36}$ See Coleman, The Practice of Principle (n 4) 179 ('On the classic understanding of it, the aim of conceptual analysis is to identify an interesting set of analytic truths about the concept that are discernible a priori'); Natalie Stoljar, 'What Do We Want Law to Be? Philosophical Analysis and the Concept of Law' in Wil Waluchow and Stefan Sciaraffa (eds), Philosophical Foundations of the Nature of Law (Oxford University Press 2013) 230, 233-234 (asserting that 'the traditional project of conceptual analysis' relies on a priori methods). 
clarified by Ayer - this philosophical practice will be, and the closer its method will be to the central case of conceptual analysis.

\section{Contemporary Analytic Philosophy and Conceptual Analysis}

Post-World War II analytic philosophy has continued to practice conceptual analysis, 'which proceeds by the analysis of meaning', ${ }^{37}$ making 'the target of philosophical analysis ... a concept, and armchair methods ... the means for eliciting the content of our concepts.$^{38}$ As with analytic philosophers of earlier generations, also contemporary practitioners of conceptual analysis determine the meaning of any given ' $X$ ' by consulting their intuitions about linguistic usage. Typically, analytic philosophers do so by asking themselves such questions as: 'Is this thing covered by "X"?'; or 'Would we say " $\mathrm{X}$ " of this thing or that "X" obtains in these circumstances?'. Asking themselves questions about the possible cases when one would or would not use a relevant word or expression enables philosophers to clarify the contours and features of relevant concepts and helps them address difficult questions involving those concepts.

Just like Ayer had argued that the philosophical clarification of concepts is not primarily a matter of providing synonymous definitions but 'definitions in use', so have the following generations of analytic philosophers enriched our understanding of what is involved in philosophical definition. For example, as Endicott and Stravroupoulos have clarified in their discussion of Hart's methodology, general legal terms apply to paradigmatic cases, as well as other cases on the ground that they are analogous to the paradigmatic ones; but this relationship of analogy does not depend on all of the non-central cases sharing the same set features. ${ }^{39}$ In cases such as this, conceptual analysis is not a matter of identifying sufficient and necessary conditions for a term to apply to certain things; ${ }^{40}$ rather, it may be a matter of identifying 'a cluster of core features', ${ }^{41}$ or 'conditions "normally" necessary and sufficient, yet "defeasible" in special circumstances'. ${ }^{42}$

There is little dispute that Hart practiced some form of conceptual analysis. ${ }^{43}$ Indeed, it would be surprising if Hart had not engaged in conceptual analysis. At the time when he was working on the lessons that would make up The Concept of Law, analytic philosophy had become the dominant philosophical

\footnotetext{
${ }^{37}$ Soames (n 27) 77.

${ }^{38}$ Kornblith (n 21) 204.

${ }^{39}$ Endicott (n 13) 42-43. Stravropoulos (n 20) 64-65.

${ }^{40}$ Some critiques of conceptual analysis fail precisely because they seem oblivious to the fact that conceptual analysis in jurisprudence often, and perhaps invariably, is not a matter of specifying sufficient and necessary conditions. Leiter, for example, has critiqued analytic philosophers' attempt at demarcating the concept of law from the concept of morality on the ground that law is a human artefact but 'human artefacts never admit of successful analysis in terms of their essential characteristics.' Leiter, 'On the Demarcation problem in Jurisprudence' (n 20), 677. This is an indictment of conceptual analysis itself, as it is conceptual analysis that for Leiter is in the business of specifying the necessary conditions for something to qualify as law rather than morality (665). It seems an indictment built on false premises. ${ }^{41}$ Stoljar (n 36), 231.

${ }^{42}$ Stravropoulos (n 20) 65. Compare Coleman, The Practice of Principle (n 4), 179. See also NW Barber, 'The Significance of the Common Understanding in Legal Theory' (2015) 35 Oxford Journal of Legal Studies 799-823, 802. ${ }^{43}$ Stravropoulos (n 20). According to Coleman, Hart himself understood his legal philosophical method as one of conceptual analysis. Jules Coleman, The Practice of Principle (n 4), 176. Dworkin famously stated that Hart was seeking to identify the criteria for the correct application of legal terms. Ronald Dworkin, Law's Empire (Belknap Press 1986) 32. Lacey, in discussing Hart's work on causation, argues that Hart's 'method ... represents a thoroughgoing application of the linguistic philosophical analysis to law ... seek[ing] to unearth the principles underlying judges' use of causal language ... and to explore the relationship between judicial usage and more general, common sense understandings of causation embedded in linguistic usage in particular contexts.' Lacey (n 3) 964. But see Marmor (n 22); and Barber (n 42), 805 (arguing that Hart 'shows little or no interest in the concept of law, and instead focuses on the nature of law as a social institution').
} 
paradigm in Britain. Hart could not have failed to be influenced by it. ${ }^{44}$ Since Hart, conceptual analysis has been 'the dominant modus operandi of jurisprudents.' 45

The most important difference between pure conceptual analysis á la Ayer and post-war conceptual analysis is the way in which the practitioners of conceptual analysis think of its point. As far as Hart himself is concerned, it is disputed whether in employing conceptual analysis he was contenting himself with describing and clarifying language ${ }^{46}$ (which would make his work continuous with the ambitions of pre-war analytic philosophy) or whether he aspired to reveal something about the nature of the thing we call 'law' law as a social phenomenon, institution or practice. ${ }^{47}$ Settling that matter about Hart is not my aim here. Instead, I want to draw attention to the point that Hart's followers, in the main, have held the latter ambition: that is, they have engaged in conceptual analysis in order to throw light on the nature of what legal concepts are concepts of. ${ }^{48}$

Pure conceptual analysis - the central case of conceptual analysis - interrogates the linguistic conventions or principles that govern the attribution of particular meanings to particular terms in order 'to dispel those confusions which arise from our imperfect understanding of certain types of sentence in our language' ${ }^{49}$ On the other hand, contemporary conceptual analysis attends to linguistic usage in order to reach 'clarity about the cases covered by the word rather than the word per se' ${ }^{50}$ For pre-World War II analytic philosophy, 'What is X?' and 'What does ' $\mathrm{X}$ " mean?' are two genuinely different kinds of questions, the former calling for empirical investigation and the latter for conceptual analysis. Providing an answer to one tells us nothing about the other. Ayer argued that if the two kinds of questions were used interchangeably in philosophy, it was only for the sake of brevity; but even when the question was put in terms of 'What is X?', in philosophy that question could only really mean 'What Does 'X" mean?'.

Philosophy... is full of questions ... which seem to be factual but are not. ... [N]o one should be deceived ... into supposing that the philosopher is engaged on an empirical or a metaphysical inquiry. We may speak loosely of him as analysing facts, or notions, or even things. But ... these are simply ways of saying that he is concerned with the definition of the corresponding words. ${ }^{51}$

There can be no a priori knowledge of reality. ... [Analytic propositions], though they may serve to guide us in our empirical search for knowledge, do not in themselves contain any information about any matter of fact. ${ }^{52}$

Not so for (most) contemporary practitioners of conceptual analysis. Rather, contemporary conceptual analysis can be seen, at least in part, as a way of approaching the question 'What is X?' through the question 'What does " $\mathrm{X}$ " mean?'. In other words, contemporary analytic philosophy has remained wedded to conceptual analysis, but it is not primarily concerned with delivering necessary analytic truths about language. Rather, it uses conceptual analysis at least partly on the ground that 'we can gain philosophical insight into some phenomenon by attending to the conceptual distinctions we use to talk and

\footnotetext{
${ }^{44}$ See Leiter, 'On the Demarcation Problem in Juriprudence' (n 20), 666, arguing that Hart was influenced by 'postWorld War II Oxford-style non-cognitivism'.

${ }^{45}$ Leiter, 'Legal Realism, Hard Positivism, and the Limits of Conceptual Analysis' (n 7), 357.

${ }^{46}$ Ian P Farrell, 'HLA Hart and the Methodology of Jurisprudence' (2006) 84 Texas Law Review 983, 1006-1007.

${ }^{47}$ Brian Leiter, Naturalizing Jurisprudence: Essays on American Legal Realism and Naturalism in Legal Philosophy (Oxford University Press 2007) 196-197.

${ }^{48}$ Dickson, Evaluation and Legal Theory (n 1), 17; Barber (n 42), 805, 816.

${ }^{49}$ Ayer (n 15), 51.

${ }^{50}$ Veronica Rodriguez Blanco, 'A Defence of Hart's Semantics as Non-Ambitious Conceptual Analysis' (2006) 9 Legal

Theory 99, 104 (paraphrasing Frank Jackson).

${ }^{51}$ Ayer (n 15) 46-47.

${ }^{52}$ Ayer (n 15) 83.
} 
think about it', ${ }^{53}$ we 'inquire into the manner in which we conceptualize our own social practices so as to ... come to a better understanding of the practices themselves' ${ }^{54}$

\section{Conceptual Analysis and Knowledge about the World}

Are contemporary analytic philosophers right in believing that conceptual analysis of ' $\mathrm{X}$ ' can yield insight into $\mathrm{X}$ as well? In this section I argue that they are, confining my arguments to analytic legal philosophy. First, I argue that even if our ultimate goal is the direct, empirical study of legal things (our Xs: law, rights, etc), we can't identify what counts as a legal thing unless we begin with an analysis of legal concepts (our 'X's: 'law', 'rights', etc). Secondly, I explain why the knowledge gained through conceptual analysis about legal ' $X$ 's also informs us about legal Xs, vindicating contemporary analytic philosophers' belief that conceptual analysis provides us with insight into the world, not just into words.

Frege, the father of modern philosophy of language, distinguishes between the sense and referent of a term. The referent is the object in the world that the term picks out. The sense is the way in which the referent becomes intelligible, or cognitively significant, to us. According to Frege, the sense of a term is a 'mode of presentation' of the referent; it 'determines' the referent. ${ }^{55}$ This distinction between sense and referent - whereby our access to the referent of a term is mediated by its sense - enables us to account for the different cognitive significance of co-referential terms or expressions (ones that share the same referent), such as 'my mother' and 'my mom'. But, as later philosophers of language have pointed out, the distinction does not seem to apply to some kinds of terms, including proper names, ${ }^{56}$ indexicals ${ }^{57}$ and natural kind terms. ${ }^{58}$ I will focus on natural kind terms, for reasons that will become obvious.

Natural kinds resist attempts at being satisfactorily defined, but they include - to give standard examples - tigers, water and gold. So 'tiger', 'water' and 'gold' are natural kind terms. In ontological terms, natural kinds have objective features that make all the specimens of the kind the specimens of that kind. Epistemologically, we are somehow able to respond, at least most of the time, to this fact about natural kinds, even if we may not always know what exactly accounts for the specimens belonging to their natural kind. ${ }^{59}$ Natural kind terms are the linguistic counterpart of this epistemological response: they track, as it were, the facticity of their referents. Whatever accounts for the specimens of a natural kind objectively belonging to that kind (something that may have to do with their physical or chemical structure or genetic distinctiveness) determines the correct usage of the natural kind term that refers to the kind. Another way of saying this is that the correct usage of a natural kind term is not fixed by convention or agreement; ${ }^{60}$ rather, it is a function of its picking out the relevant kind in a way that is true to that kind's ontological facticity (or, more accurately, to the scientific statements that constitute our best approximation of that facticity). On this view, if ligers looked exactly like tigers and, in ignorance of their distinctive genetic make-up, we called them 'tigers' alongside real tigers, we would be mistaken. This makes natural kind terms directly referring expressions - terms whose referent is not mediated by a sense. In the case of natural kind terms the term's

\footnotetext{
${ }^{53}$ Leiter and Langlinais (n 20), 5.

${ }^{54}$ Perry (n 5) 314. See also Rodriguez Blanco, 'A Defence of Hart's Semantics as Non-Ambitious Conceptual Analysis' (n 50), 108.

${ }^{55}$ For an introductory discussion to these ideas see Gary Kemp, What Is This Thing Called Philosophy of

Language?(Routledge, 2013).

${ }^{56} \mathrm{Kemp}$ (n 55), 59.

${ }^{57}$ Kemp (n 55), 83.

${ }^{58}$ Compare Kemp (n 55), 64-65.

${ }^{59}$ See Kirk Ludwig, 'Methods in Analytic Epistemology' in Matthew C Haug (ed), Philosophical Methodology: The Armchair or the Laboratory (Routledge 2014) 217, 230-231.

${ }^{60}$ Even natural kinds are actually partially conventional (Hilary Putnam, Renewing Philosophy (Harvard University Press 1992) 112-115), but I can ignore these complexities for the purposes of my discussion in the text.
} 
meaning is then not its sense, but its referent. ${ }^{61}$ But since it is the sciences that supply us with the best knowledge about the referents of natural kind terms, on this view there is nothing or little of interest for conceptual analysis to contribute in relation to natural kinds.

If 'law' functioned like a natural kind term, ${ }^{62}$ linguistic analysis would not be a promising way to learn anything about law: indeed, if philosophy's task is to engage in conceptual clarification, then there would be no knowledge about law that philosophy could contribute because there would be no concept of law (no sense of 'law') to be clarified. If 'law', like natural kind terms, is directly referring, then to understand what law is one must give up philosophical (language-focused) analysis of 'law' and directly carry out empirical investigation into the term's referent - law without quotation marks. Some structuralists might think about law precisely along these lines. They might think that law is a universal structure of human societies whose facticity forces itself, as it were, upon our cognition. The expression 'law' would then do no more than track the facticity of law - like a natural kind term tracks the facticity of the natural kind - and learning about law would require us to observe the referent law, not analysing the meaning of 'law'. Analytic jurisprudence would then be a waste of time.

Fortunately for analytic jurisprudence and its methodological focus on conceptual analysis, it is highly implausible to suppose that 'law' is a directly referring term. One does not and cannot point to 'law"s referent in order to clarify the meaning of 'law' in the same way that one points to a tiger to clarify the meaning of the natural kind term 'tiger' (or to John in order to clarify who goes by the proper name 'John', or to the object to which 'this' refers in order to clarify what one means by the use of the indexical 'this' in the context of any given utterance). If one were asked 'What is law?', one would naturally proceed by way of something like a descriptive definition purporting to give the sense of 'law'. A linguistic account seems the obvious place to start because law is a social practice, a human creation, ${ }^{63}$ rather than an ontologically independent entity like natural kinds. There is no way of getting to law (the referent of 'law') other than through the sense of 'law' - the sense of an expression being precisely what determines the referent of the expression. So to learn about law, it would seem that one must at least start with 'law'; for the term's referent is determined by the term's sense (by the concept of law). ${ }^{64}$

Once the referent is identified, one can proceed to study it in its own right to establish synthetic truths about it. Thus, if an analysis of 'law' reveals that law is partly to do with judicial decision-making, there will be much to learn about law from observing the behaviour of judges in courts. But these empirical investigations are dependent on at least a modicum of prior conceptual work, without which the referent would remain underdetermined.$^{65}$ From this perspective, the questions 'What does 'law' mean?' and 'What is law?' are not necessarily coextensive, but the former is a necessary part of the latter.

We have seen that it is distinctive of post-Hartian analytic jurisprudence to analyse legal conceptwords ('X's) in order to explain the nature of what they are concepts of (Xs). Drawing on Farrell's argument that conceptual analysis is defensible if and only if it aims to describe 'the concept and not ... the world" ${ }^{66}$ (that is, the sense and not the referent), Leiter has taken issue with legal philosophers' immodest ambition, in

\footnotetext{
${ }^{61}$ Soames (n 27), 90.

${ }^{62}$ Stravropoulos has made a suggestion to the effect that 'law' might indeed work as a natural kind term. Stravropoulos (n 20) 81-84. But, as he points out, this suggestion is subject to 'serious objections' and his aim in making it was only to show that (his rendition of) Hart's methodology 'faces strong competition in the philosophy of language and mind by a number of approaches' (84).

${ }^{63}$ Leiter, 'Legal Realism, Hard Positivism, and the Limits of Conceptual Analysis' (n 7), 358; Leiter, 'On the Demarcation Problem in Jurisprudence' (n 20), 666.

${ }^{64}$ For some similar points see Farrell (n 46), 1002-1003; Brian Leiter, 'Naturalized Jurisprudence and American Legal Realism Revisited' (2011) 30 Law and Philosophy 499, 512-514; Dworkin, 'Hart's Postscript and the Character of Political Philosophy' (n 5), 10-11; Barber (n 42), 809-810. But see Marmor (n 22), 217.

${ }^{65}$ Compare Stravropoulos (n 20) 70 (arguing that conceptual analysis 'is supposed to define the subject of inquiry').

${ }^{66}$ Farrell (n 46), 999.
} 
using conceptual analysis, to illuminate not only the concept but also the world ${ }^{67}$ Dickson finds puzzling Leiter's claim that it is immodest for conceptual analysis in jurisprudence to presume to tell us anything about the world. ${ }^{68}$ There are good reasons to share Dickson's reaction. First, if the referent of a concept-word becomes cognitively significant to us through the concept-word's sense - if we come to know many of the things in this world through the concepts that apply to them - clarifying the sense does, by definition, deliver important knowledge about the referent. ${ }^{69}$ Secondly, if, as we have seen when discussing Ayer, conceptual definitions are often the result of entrenching in language synthetic generalisations about the world, such definitions will tend to be informative about the world, albeit not in the sense of establishing irrefutable truths. Thirdly, conceptual explanations are always incomplete. It could not be otherwise: a term's sense is only one mode of presentation of the referent. ${ }^{70}$ As Raz puts it, concepts pick out that of which they are concepts of in particular ways, by focusing on some of their features rather than others; and conceptual explanations reflect this feature of concepts. ${ }^{71}$ So while conceptual accounts yield knowledge on the referents of concept-words, this remains necessarily partial knowledge (even in the case of accounts aiming at relative comprehensiveness). Analytic philosophers, to my knowledge, do not claim otherwise. Their accounts, that is, are modest in the relevant sense of the word: not because they implausibly deny that clarifying concepts also informs us about their referents, but because they are aware that such information is necessarily partial.

\section{The Naturalistic Challenge}

The argument in the previous section was to the effect that conceptual analysis in jurisprudence is 'the prologue' to the study of 'the nature of things "72 - that a linguistic account of 'law' is the obvious and necessary place to start when inquiring into law. Some appear to deny this. Leiter, for example, appears to suggest that it is the other way round. Rather than analysis of legal concepts enabling us to identify legal things, so that we can then proceed to empirically study their nature, he argues that empirically predictive explanations about the nature of certain things inform us about the correct meaning of legal concepts. In this section I respond to this claim.

Leiter has been the most vocal and dedicated critic of conceptual analysis in jurisprudence, although his critique has changed over time. ${ }^{73}$ His argument proceeds from within the framework of naturalism, which indicts conceptual analysis and all armchair methods of inquiry for their unreliability, demanding that they either be replaced by or framed within empirical scientific theories. ${ }^{74}$ Naturalism requires, at a minimum, that

\footnotetext{
${ }^{67}$ Leiter, Naturalizing Jurisprudence (n 47), 186, 189-190. But see Marmor, who, unlike Farrell, does not maintain that (Hart's) conceptual analysis in law has been of the modest (defensible) variety (aiming to describe the concept and not the world); rather he argues that jurisprudence is reductionist - that is, that it has aimed to explain the world and, appropriately, has not actually employed conceptual analysis in order to do so. Marmor, like Leiter, concedes that conceptual analysis matters, but not quite as much as knowledge about the real world, which it cannot deliver. Marmor (n 22), 213.

${ }^{68}$ Julie Dickson, 'On Naturalizing Jurisprudence: Some Comments on Brian Leiter's View of What Jurisprudence Should Become' (2011) 30 Law and Philosophy 477, 489.

${ }^{69}$ Leiter's most recent work seems to accept something like this point where it states that 'the metaphysics of a social construct like law precludes deference to the empirical sciences for the purposes of general jurisprudence, since the way people use and understand the concept just constitutes the fact in question'. Nonetheless, he still holds on to his naturalist objections ('Yet this kind of argument does not wholly deflect the naturalist's challenge'), without really resolving the tension. Leiter and Langlinais (n 20), 13.

${ }^{70}$ Kemp (n 55), 20.

${ }^{71}$ Raz, 'Two Views on the Nature of Law' (n 4), 8, 19.

${ }^{72}$ Stravropoulos (n 20) 69.

${ }^{73}$ Brian Leiter, 'Naturalized Jurisprudence and American Legal Realism Revisited' (n 64) 511; Dickson, 'On Naturalizing Jurisprudence' (n 68), 485, 486.

${ }^{74}$ Leiter, Naturalizing Jurisprudence (n 47), 31-33; Leiter, 'Naturalized Jurisprudence and American Legal Realism Revisited' (n 64), 510-511. While Leiter has now become less optimistic about the ability of the social sciences to
} 
philosophical truths be confirmed empirically or scientifically. ${ }^{75}$ Leiter suggests one possible way of naturalising jurisprudence precisely along these lines: when looking, for example, for the correct answer to the question of what the concept of law is, we should settle for the one that 'figures in the most powerful explanatory and predictive models of legal phenomena such as judicial behaviour. ${ }^{76}$ Leiter uses, as an example, empirical research on the determinants of outcomes in judicial decision-making. He says that the best predictive model (whose predictive power, he concedes, nonetheless remains relatively weak) ${ }^{77}$ identifies those determinants not with legal materials - understood as precedents, statutes and constitutional documents - but with the facts of a case combined with the judges' ideological attitudes and values. He goes on to argue that a particular hard positivist ${ }^{78}$ concept of law is presupposed and vindicated by this model, since the model identifies legal materials in a way that conforms with that concept, thereby excluding moral/ideological values from the realm of legal materials; otherwise the study could not make moral/ideological values an independent candidate for the role of determining judicial behaviour. It follows that not only does the concept of law figure in this study (as a presupposition), but that the study also gives us reason to believe that hard positivism correctly identifies that concept. ${ }^{79}$ Leiter also argues that if the sciences have no use for many of the concepts that interest legal philosophers - so that such concepts do not figure, even implicitly, in scientists' explanatory and predictive models of legal phenomena - then these concepts are of no interest and not worth their philosophical salt, 'absent some independent argument against the ... assumption that it is within science itself and not in some prior philosophy, that reality is to be identified and described. ${ }^{80}$

Effectively, Leiter is making two interconnected claims against conceptual analysis in jurisprudence: that only those legal concepts matter that are useful to social science and that their content is fixed in whatever way makes the concepts serviceable for social science. But these claims are dubious. It is, of course, for empirical social scientists to postulate whatever categories are most serviceable to the construction of predictive models about any given social phenomenon they choose to study. It is also for them to call these categories whatever they like. But just because they choose to give their explanatorily or predictively useful categories the same names we use for our legal concepts does not mean that these categories are then our legal concepts. The point may become clearer if we consider Perry's articulation of what would be involved in developing a non-hermeneutic theory of law. ${ }^{81}$ Perry does not defend this approach, ${ }^{82}$ but it is instructive to quote from the passage where he describes it. This approach

supposes that what does and does not count as law is determined by applying the scientific method to come up with a ... descriptive-explanatory theory. The idea would be to study those social practices that we call law, but from an external perspective. Taking a certain kind of familiar social practice ... as a tentative starting-point, a theory of this kind would develop its own internal descriptive categories. These categories would not necessarily correspond to what 'we' ... have in mind, either explicitly or implicitly, in speaking of 'law'. To the extent that a descriptive-explanatory theory used

explain and predict legal phenomena, he still thinks it is possible that social science will mature to the point of 'warrant[ing] epistemic confidence'. Leiter, 'Naturalized Jurisprudence and American Legal Realism Revisited' (n 64), 511. It is important to show, therefore, that conceptual analysis in jurisprudence is not a second-best method whose validity is somehow contingent on the social sciences acquiring the ability to provide us with reliable knowledge about legal phenomena.

${ }^{75}$ Leiter, Naturalizing Jurisprudence (n 47), 34.

${ }^{76}$ Leiter, Naturalizing Jurisprudence (n 47), 184

${ }^{77}$ Leiter, Naturalizing Jurisprudence (n 47), 192.

${ }^{78}$ For hard positivism whether a legal rule is legally valid never depends on whether it is morally sound.

${ }^{79}$ Leiter, Naturalizing Jurisprudence (n 47), 189.

${ }^{80}$ Leiter, Naturalizing Jurisprudence (n 47), 185.

${ }^{81}$ Perry (n 5), 311-354.

${ }^{82}$ Perry (n 5), 348. 
the term 'law', ... [i]ts meaning and extension would be determined by the relative explanatory power of accepting one way of categorizing and describing social practices over another. ${ }^{83}$

As this description reveals, such an approach does not abstain from the linguistic considerations typical of conceptual analysis ('to study those social practices that we call law ... [t]aking a certain kind of familiar social practice ... as a tentative starting-point'), ${ }^{84}$ albeit probing rather more superficially than conceptual analysis into the meaning of 'law'. After all, if it did so abstain, it could hardly claim to be providing a theory of 'law'. But the approach then commits itself to incoherence by giving up on that claim altogether, where it gives itself license to radically redefine the category 'law' in light of 'such standard metatheoretical criteria as ... predictive power, coherence, range of phenomena explained, degree of explanatory unity, and the theory's simplicity or elegance. ${ }^{85}$ There is nothing wrong with 'taking a certain kind of familiar social practice ... as a tentative starting-point' and then developing 'one's own internal descriptive categories' that may have nothing to do with 'what "we" ... have in mind ... in speaking of "law". ${ }^{86}$ The problem is with trying to pass off the resultant theory as an account of law. ${ }^{87}$

Similarly, to return to Leiter's example, there is much to learn from an empirical study that shows that judicial outcomes are determined less by statutes, precedents and constitutional documents (which the researchers happen to choose to designate as 'legal' materials) than by judicial moral values (which the researchers happen to choose to characterize as non-legal). But it is a non-sequitur that it is thereby correct to understand the concept of law in a way that denies that moral tests can ever be tests for legal validity.

The claim that the priorities of social scientists should determine the content of our legal concepts is predicated on the assumption that it is not worth pursuing conceptual analysis as a way of understanding how we make sense of the world through our use of terms such as 'law'. But this assumption is arbitrary. As we know, 'law' and other legal terms are not directly referring expressions: they have senses that mediate between them and their referents. These senses are just our concepts. It is intrinsically interesting and instrumentally valuable to understand the ways in which these concepts make the world cognitively significant to us, regardless of whether or not these concepts happen to be of use to social scientific research. ${ }^{88}$

\section{Beyond the Central Case}

I have argued that contemporary conceptual analysis aims to yield insight not just into words, but also into the world. I have also argued that this claim is plausible, albeit conceding that there remains much about the world that social scientific research - whose work is enabled by conceptual analysis - is better placed to investigate. The other main feature of post-World War II conceptual analysis in jurisprudence is that it has given up the aspiration to be analytic in the strict sense of the word: as I argue in this section, contemporary conceptual analysis differs from the central case because it is only partially a priori and it does not aim at yielding analytic truths.

\footnotetext{
${ }^{83}$ Perry (n 5), 313-314.

${ }^{84}$ Perry (n 5), 313-314.

${ }^{85}$ Perry (n 5), 314.

${ }^{86}$ Perry (n 5), 314.

${ }^{87}$ See Barber (n 42), 808-809.

${ }^{88}$ Leiter appears aware of the force of this argument, or something like it; curiously, however, he seems reluctant to accept its implications for his argument about the subordination of analytic jurisprudence to social science. Leiter, Naturalizing Jurisprudence (n 47), 186-196.
} 
There is virtual agreement on the point that contemporary conceptual analysis is not merely a matter of recording folk uses of terms.$^{89}$ Rather, the analytic philosopher may play a role in partially shaping the concept under study. ${ }^{90}$ Indeed, even Ayer conceded, in a footnote to his discussion of the analytic character of philosophical inquiry, that 'the philosopher is always concerned with an artificial language [because] the conventions which we follow in our actual usage of words are not altogether systematic and precise'. ${ }^{91}$ Marmor is virtually alone in arguing that 'conceptual analysis cannot be revisionist': concept revision, he claims, is legitimate if it serves a theoretical purpose, but that does not make it an instance of conceptual analysis. ${ }^{92}$ I will argue below that this dichotomy is too crude. Wholesale revision is not conceptual analysis; but partial revision qualifies as conceptual analysis, thought not as the central case of conceptual analysis. Ironically, Marmor's apparently conceptual claim that conceptual analysis cannot be revisionist is itself revisionist, for, as I argued, virtually all other legal philosophers understand conceptual analysis to embrace partially revisionist projects. The (partially) revisionist character of conceptual analysis is significant because, as I will explain, in revising folk concepts analytic philosophers may rely on a posteriori (empirical) knowledge rather than merely their a priori linguistic (and logical) competence.

At a minimum, conceptual analysis exceeds the exercise of reporting on folk usages of a particular concept because it will follow Hart in aiming to rationalize folk usage of concept-words 'and to project from that to ... a norm that guides actual usage'. Hart did so by making 'explicit ... the latent principle that guides our use of words', with 'actual usage set[ting] limit to such a projection' ${ }^{93}$ But conceptual analysis may be more revisionist than this. Concepts can be significantly contested, ${ }^{94}$ inviting the philosopher to tidy them up. Furthermore, as Raz explains, there is typically 'no uniquely correct explanation of a concept', but a number of alternative explanations, whose value is relative 'to the interests and capacities of their public' and which are 'incomplete' because they focus on 'puzzling or troubling aspects of concepts' rather than aiming at comprehensiveness. ${ }^{95}$ Philosophical conceptual explanations, however, are more ambitious in seeking 'a more systematic understanding', a relatively 'more comprehensive explanation' ${ }^{96}$ This leads philosophical explanations to adopt 'a freer attitude to existing practice', which involves making the explanation less vague than the concept itself, and introducing 'distinctions between different uses or senses of the terms or phrases used to express the concept ... which redraw somewhat the boundaries of the concept' ${ }^{97}$ Raz qualifies this last point, however, by stating that 'the reduction in vagueness can only be limited, or the explanation will not be true to the concept explained'. ${ }^{98}$

The implication is that not only do philosophers identify some uses of a term as plausible and some as implausible in light of the standards implicit in actual (folk) usage; but they are also able to explain why

\footnotetext{
${ }^{89}$ Coleman, The Practice of Principle (n 4), 176-177; Stoljar (n 36), 232; Leiter and Langlinais (n 20), 10; Dickson, 'Methodology in Jurisprudence' (n 2), 132, 138; Stravropoulos (n 20) 74-75; Lacey (n 3), 962; Rodriguez Blanco, 'A Defence of Hart's Semantics as Non-Ambitious Conceptual Analysis' (n 50), 111-116.

${ }^{90}$ Barber (n 42) 798 (arguing that we can understand, as Raz and Hart understand, conceptual analysis 'as the examination and refinement of the common understanding of phenomena' (emphasis added)).

${ }^{91}$ Ayer (n 15), 61.

${ }^{92}$ Marmor (n 22), 212.

${ }^{93}$ Stravropoulos (n 20) 81. But see Rodriguez Blanco, 'A Defence of Hart's Semantics as Non-Ambitious Conceptual Analysis' (n 50), 108-116, disputing that this is an accurate characterisation of Hart's approach.

${ }^{94}$ Barber (n 42), 814-816.

${ }^{95}$ Raz, 'Two Views on the Nature of Law' (n 4), 10.

${ }^{96} \mathrm{Raz}$, 'Two Views on the Nature of Law'(n 4), 25-26.

${ }^{97}$ Raz, 'Two Views on the Nature of Law' (n 4), 26. See also Raz, Ethics in the Public Domain (n 3), 237.

${ }^{98}$ Raz, 'Two Views on the Nature of Law' (n 4), 26. This is why I think that, if Marmor includes too little into the category of conceptual analysis (by excluding all revisionist projects), Stoljar and Haslanger perhaps include a little too much where they take it to cover "ameliorative inquiry that theorizes about our "legitimate purposes" in using a concept and yields a target concept' (Stoljar (n 36), 232), at least if they allow (as they seem to: Stoljar (n 36), 237-239) for the possibility that the target concept could be a wholesale revision of the folk concept. Including ameliorative inquiry of this kind into the category of conceptual analysis dispenses with the conceptual distinctiveness of conceptual analysis.
} 
some uses may be finer or sharper than others. In doing so, they will draw attention to certain intuitions that underlie the sharper or finer usages of a term, of which the users themselves are not typically aware. I want to claim that we can identify intuitions at three different levels, on a continuum that moves from the formal to the substantive. First, intuitions about linguistic and semantic economy and determinacy may be relevant. A community of speakers may have an aesthetic preference and/or a functional need for precision and consistency, for example, and a sharper or finer usage of a term - one that satisfies that preference or need has a greater claim to correctly identify the meaning of the concept-word.

Secondly, the analytic philosopher can clarify and refine a folk concept by attempting to align it more fully with the most central intuitions about its meaning, so as to do full justice to these intuitions. This will typically be at the cost of discounting other less significant (albeit perhaps widespread) intuitions that govern the usage of the concept-word. For example, while Hart recognized that the folk concept of law treats coercion as central to it, he thought that 'we will fail to do justice to other important features of the folk concept $\ldots$ if we overstate its role' in the way unreflective, ordinary understandings of 'law' tend to do. ${ }^{99}$

But, thirdly, to speak of intuitions that underlie the sharper or finer usages of a term also suggests that a community of speakers, or some of its members, may have a hunch (which without the philosopher's aid they would be unable to articulate) of a more substantive kind. This is a hunch about the ways in which language should relate to the world, and particularly about how a certain term should relate to its referent. The fact that folk concepts may have a tendency to accurately pick out important features of the phenomena to which they apply does not guarantee that they always do. ${ }^{100}$ To say this is to suggest that a term's correct meaning (its sense) is not purely contingently fixed by convention: it is not the case, that is, that the world is made up of a wholly inchoate reality which we organize through meaning-making practices in wholly accidental ways. These practices are, rather, constrained by the object the concept describes: even when the referent of a term is a composite and largely intangible thing such as a social practice, this (or some of the entities, phenomena, etc of which it is made up) may still have an internal logic or objective features, which the sense of the term should be responsive to, not distort or obscure. ${ }^{101}$

To be sure, the concerns of human beings will determine the significance of different features of the practice; it is only because of those concerns that anything like a logic may be detected in the practice at all. So unlike natural kind terms, it is not a case here of the referent directly supplying the meaning of the term; ${ }^{102}$ the sense here still mediates between the term and the referent, not only in determining the significance of the referent but also, as a mode of presentation of the referent, in constructing the referent itself. ${ }^{103}$ But this is not construction all the way down: the referent retains a facticity to which the sense needs to remain faithful. ${ }^{104}$

At this third, substantive level of intuitions about the finer or sharper usages of a concept-word, the analytic philosopher will determine the correct or relevant meaning of a given term having recourse not only to linguistic conventions governing the usage of the concept-word but also to information supplied by

\footnotetext{
${ }^{99}$ Leiter and Langlinais (n 20), 11-12.

${ }^{100}$ Barber (n 42), 811-812, 819-822.

${ }^{101}$ See also Rodriguez Blanco, ‘A Defence of Hart's Semantics as Non-Ambitious Conceptual Analysis' (n 50), 116:

'The theorist analyzes concepts but accepts the limitations of conceptual analysis and therefore uses empirical knowledge and substantive arguments to explain, refine, or perhaps refute initial insights provided by intuitions.' In constructing his case against his understanding of Hart's methodology, Stravropoulos makes a similar point, though he overstates it by implying that legal concepts may be just like natural kinds. Stravropoulos (n 20) 82-83.

102 But see Stoljar (n 36), 236, who has recently argued that there are cases of 'social externalism' - namely, situations in which social kinds work just like natural kinds, so that the meaning of the corresponding terms is a function of 'the nature of the kind to which the [term] refers' rather than 'conventional usage'.

${ }^{103}$ Compare Barber (n 42), 809-810.

${ }^{104}$ From this perspective, it is an overstatement to claim that 'there is no true law beyond our understanding and usage' (Farrell (n 46), 1007) and that 'legal phenomena ... are wholly constituted by the beliefs and attitudes ... linguistic practices reveal' (Leiter and Langlinais (n 20), 8).
} 
observation of and/or experientially-informed speculation about the referent. For instance, Lacey points out that Hart was committed 'to producing ... a theory of law that would ... fit the facts', ${ }^{105}$ and that 'the tension between the project of analysing legal usage .. and the idea that there is an essential core to' legal phenomena ${ }^{106}$ ' is thrown up into sharp relief by the method of moving back and forth between actual usage and philosophical refinement'. ${ }^{107}$

To the extent that conceptual analysis is revisionist, and particularly to the extent that analytic philosophers consult something other than linguistic conventions in order to determine the meaning of a term, the descriptive definition that will result from the investigation, assuming it is a truth, will not be true in the analytic sense: it will not be true merely by virtue of meaning as fixed by linguistic conventions knowable a priori. Thus the elucidation of legal concepts may be only partly a matter of linguistic analysis. ${ }^{108}$ But the fact that the revisionist character of conceptual analysis precludes it from yielding truths in the strictly 'analytic' sense does not mean that it is unimportant or pointless. Indeed, it is precisely a sense of the limited philosophical interest of non-revisionist conceptual analytic accounts that drives philosophers towards revisionist conceptual analysis, even at the cost of renouncing the prospect of establishing analytic truths.

The revisionist character of conceptual analysis also suggests one way of interpreting the oft-made claim that conceptual analysis has not much to do with the meaning of words and that it is not lexicography. ${ }^{109}$ Raz's objection to understanding conceptual analysis in terms of linguistic analysis, for example, ultimately seems to turn on his view that linguistic analysis of legal concept-words is 'inconclusive'. ${ }^{110} \mathrm{He}$ seems to argue that there is no settled, conventionally agreed upon meaning for terms such as 'law' or 'legally' that will throw light upon the nature of law as that particular practice that is of distinctive interest to legal philosophy because of the way in which it structures people's understandings of 'their own and other people's actions'. ${ }^{111}$ Because of this, understanding law is not a matter of understanding the meaning of these words. ${ }^{112}$ It seems preferable to say that conceptual analysis exceeds linguistic analysis, not in the sense that the philosopher in these cases is not in the business of identifying and articulating one of the meanings of legal concept-words, ${ }^{113}$ but in the sense that in these cases one assigns meaning on some basis other than reliance on settled linguistic conventions. This more complex way of assigning meaning may involve, as we have seen, experientially-informed speculation on the significant features and/or logic of the term's referent (possibly even empirical observation of the referent). The descriptive definition of the concept-word that will result from this investigation, assuming it is a truth, will not be true in the analytic sense. But none of this means that conceptual analysis has not much to do with the meaning words.

There may be other reasons why conceptual analysis is not reducible to linguistic analysis. Methodological anti-positivism, if sound, suggests one - namely, that at least certain kinds of concepts

\footnotetext{
105 Lacey (n 3) 949.

${ }^{106}$ Lacey (n 3) 950.

${ }^{107}$ Lacey (n 3) 992. which were previously uncertain' (997).

${ }^{110}$ Raz, Ethics in the Public Domain (n 3), 204.

${ }^{111}$ Raz, Ethics in the Public Domain (n 3), 237.

${ }^{112}$ Raz, Ethics in the Public Domain (n 3), 196-198.

${ }^{113}$ But see notes $115-117$ and accompanying text.
}

${ }^{108}$ Stoljar similarly argues that 'conceptual analysis ... often transcends what we have in mind and what could be articulated through an examination of common understanding'. Stoljar (n 36), 236. Stoljar makes the point in relation to cases of 'social externalism' (see note 102), but the point can be generalized.

${ }^{109}$ Raz, Ethics in the Public Domain (n 3), 198; Leiter, 'Legal Realism, Hard Positivism, and the Limits of Conceptual Analysis' (n 7), 358. Farrell usefully suggests that one of the sense in which conceptual analysis is not lexicography is that lexicography, unlike conceptual analysis, simply lists or identifies 'disparate usages of a word' but it 'does not ... purport to provide an underlying theory that ties [them] together'. Farrell (n 46), 1001. Because conceptual analysis, on the other hand, develops such a theory, Farrell argues, 'we are then able to apply this theory to attain answers in cases 
cannot be accounted for without engaging in moral evaluation. I refrain from discussing this point a length for the reasons mentioned earlier in the paper. I will limit my remarks to the following two. First, practitioners of conceptual analysis can easily accept that some concepts cannot be accounted for without engaging in moral evaluation ${ }^{114}$ - after all, this claim sits well with the idea of conceptual analysis's revisionist character. But, secondly, revising a folk concept in light of moral considerations can only go so far: as with all kinds of folk concept revision in conceptual analysis, revision can only be partial.

Another reason why conceptual analysis is not reducible to linguistic analysis follows from the fact that having a concept does not necessarily require us to have a distinctive word or standard expression for it. ${ }^{115}$ Since words and concepts are intimately related, ${ }^{116}$ such cases are relatively unusual, but they may occur. Conceptual clarification here may proceed by analysing the meaning of things we may say about such a concept, even if there are no standard terms or expressions conventionally used to express the concept. But it could also proceed, for example, by way of observing cultural artefacts that non-linguistically express the concept. This last kind of investigation seems a posteriori, or includes an a posteriori element. ${ }^{117}$ In sum, if meaning-making is not merely a function of attaching a specific term or standard expression to a particular referent, or indeed of saying anything about it in linguistic form, then clarification of concepts need not always be about linguistic analysis and a priori.

\section{Another Naturalistic Challenge}

Conceptual analysis, as we have seen in the previous section, is not necessarily always a priori, in the sense that it often calls for more than reliance on the philosopher's linguistic competence - requiring one to reflect about or, even better, empirically study the referents of concept-words or non-linguistic meaning-making practices. But then why be contented with the philosopher's own competence as far as linguistic practices themselves are concerned? Should philosophers not, in their attempt at uncovering the meaning of conceptwords, heed naturalism's call to 'emulate the "methods" of inquiry and styles of explanation characteristic of successful sciences'? ${ }^{118}$

Socio-legal science can take some legal concepts as its very object of analysis and, like analytic philosophy, aim to clarify their meanings. Leiter recommends precisely that legal philosophers should turn into social scientists, making their philosophy 'experimental'. ${ }^{119}$ Because the analytic philosopher's 'process of discovering the initial data to be subjected to philosophical analysis may ... be undertaken a posteriori by ... conducting surveys of what people think they mean by their words or concepts', ${ }^{120}$ there is clearly continuity between this kind of empirical research into the content of legal concepts and analytic jurisprudence. Nonetheless, as Dickson points out, empirical research into legal concepts is no substitute for conceptual analysis, which, as we have seen, is interested not just in recording, but in rationalising and

\footnotetext{
114 Whether or not law is one of these concepts is of course much more controversial.

115 Raz, 'Two Views on the Nature of Law' (n 4), 7-8.

${ }^{116}$ Leiter, 'Legal Realism, Hard Positivism, and the Limits of Conceptual Analysis' (n 7), 358.

${ }^{117}$ Consider, for example, the Japanese term 'mono no aware', pointing to something like (the aesthetic value of) the bitter-sweet feeling of melancholy engendered by the awareness of the transience of things. Starting from this information, it may be plausible not only for social scientists to carry out a posteriori research into that feeling as experienced by English-speaking people, but also for philosophers to engage in a priori reflection about the sort of things (if any) that we may say about such a feeling. Or they could look to relevant non-linguistic (for example pictorial) representations and use them to clarify the cognitive significance (if any) of that feeling for us. This may reveal that we have a concept of mono no aware even if we lack a direct English equivalent of the term itself.

${ }^{118}$ Leiter, Naturalizing Jurisprudence (n 47), 34.

${ }^{119}$ Leiter, Naturalizing Jurisprudence (n 47), 192-193. Presumably this recommendation is meant to apply only to those legal concepts that Leiter thinks matter, namely those that figure in scientific models that have strong predictive or explanatory power.

${ }^{120}$ Stoljar (n 36), 230-253, .
} 
illuminating the use of our concept-words. ${ }^{121}$ I want to build on Dickson's point as I believe it offers precisely the 'independent argument against the ... assumption that it is within science itself and not in some prior philosophy, that reality is to be identified and described' - an argument that Leiter feels is required in order to respond to the naturalistic challenge to jurisprudence. ${ }^{122}$

Empirical research into what the folk mean by 'law' could be quantitative and attempt to determine, say, recurrent and statistically significant elements or trends in folk understandings of 'law'. In doing so it would inevitably have to simplify, flatten differences, and settle on a relatively shallow concept of law - a minimum common denominator. Alternatively, empirical research about the concept of law could be qualitative, deep and rich focusing on a number of small participants, and aiming to come up with an account that shows each understanding in all its uniqueness, resisting the urge to reduce any one understanding to the next and manufacture coherence among them. Where does conceptual analysis stand vis-à-vis the qualitative/quantitative divide? The point of conceptual analysis is to provide neither a minimum common denominator of shared usage, ${ }^{123}$ nor a snapshot of the rich variability in usage by different folks. Yet conceptual analysis has both quantitative and qualitative elements. Its has a quantitative element because of its use of intuitions about the cases covered by folk linguistic usage; but it also has a qualitative element because it probes into those usages as deeply as only a true participant in the linguistic and conceptual practices it analyses could venture. Through its use of conceptual analysis, analytic philosophy can provide accounts that are at one time deep (like qualitative accounts) and unified (like quantitative ones). Analytic philosophy can do so without committing itself to incoherence because its aspirations are partially revisionist - to rationalize usage of the concept in a bid to increase our self-understanding - and because conceptual analysis is just the method that suits these aspirations. In particular, as we have seen, through conceptual analysis philosophers mediate between reporting and revision in light of the most central intuitions that inform linguistic usage, or guided by the logic of the sharper instances of such usage. ${ }^{124}$

But then what are 'the criteria ... by which the theorist sorts the wheat from the chaff'? ${ }^{125}$ There are three (related) ways of answering this question. The first is to respond that conceptual analysis already adequately clarifies its methodology to the extent that it explains (or shows) that it proceeds largely by way of intuitions about language and judgements about the relative importance of these intuitions. The success of the accounts it provides is to be measured by their ability to illuminate our meaning-making practices, not by the philosopher's ability to articulate beforehand the exact criteria by which one will exercise judgement every step of the way. If new knowledge were held hostage to the latter requirement, there would be very little knowledge to advance indeed. A second answer, building on the first, is that in exercising judgement the philosopher will be guided by (further) intuitions about what will result in an account that will in fact succeed at increasing our self-understanding and at illuminating a concept-word's usage (either folk usage or usage in some specialist field). A third response - though I can do no more than gesture towards it - points to the idea of reflective equilibrium. ${ }^{126}$ Philosophers, in other words, discriminate among intuitions not only on

\footnotetext{
${ }^{121}$ Dickson, 'On Naturalizing Jurisprudence' (n 68), 491-494.

${ }^{122}$ Leiter, Naturalizing Jurisprudence (n 47), 187; Leiter, 'Naturalized Jurisprudence and American Legal Realism Revisited' (n 64), 514-515.

${ }^{123}$ As Coleman clarifies, '[w] hile the meaning of a term or of the concept it expresses is of course intimately bound up with its use, that subtle relationship could never be captured by a simple reporting project aimed at tabulating commonalities of shared usage.' Coleman, The Practice of Principle (n 4), 178.

${ }^{124}$ In so doing, conceptual analysis by-passes the controversy about whether it is epistemologically tenable to combine quantitative and qualitative methods. On this controversy see Alan Bryman, 'The Debate about Quantitative and Qualitative Research: A Question of Method or Epistemology?' (1984) 35 The British Journal of Sociology 75; Joanna EM Sale, 'Revisiting the Quantitative Qualitative Debate: Implications for mixed-Methods Research' (2002) 36 Quality and Quantity 43.

${ }^{125}$ Leiter, 'Naturalized Jurisprudence and American Legal Realism Revisited' (n 64), 516.

${ }^{126}$ Note that Haslanger describes the method of the most basic kind of conceptual analysis as follows: 'Taking into account intuitions about cases and principles, one hopes eventually to reach a reflective equilibrium.' Sally Haslanger,
} 
the ground that some appear plainly erroneous, but also by constructing more general propositions on the basis of the intuitions that are not plainly erroneous and moving back and forth between the general propositions and the intuitions, so as to achieve coherence between them, both by adjusting and integrating the general propositions and by discarding recalcitrant intuitions. To paraphrase Goodman: 'The process of justification is the delicate one of making mutual adjustments between [intuitions] and [propositions]; and in the agreement thus achieved lies the only justification needed for either'. ${ }^{127}$

\section{Conceptual Analysis and Armchair Theorising}

Although, in its revisionist character, conceptual analysis necessarily exceeds the qualitative or quantitative empirical study on the usage of concept-words, empirical research may have considerable informative value for conceptual analysis. It does not follow that conceptual accounts must be suspect unless they are explicitly informed by such empirical studies. Philosophers, after all, may be reasonably presumed to be as competent users as any of the linguistic-conceptual apparatus they are interested in illuminating and rationalising - or this is one of the key presuppositions making up the analytic philosophical paradigm.

It gets more complicated when a philosopher, rather than aiming to tell us something about the sense of concept-words (and indirectly about their referents), aims to describe and explain the nature of referents in their own right, without the support of empirical evidence. Yet, according to Raz, conceptual analysis is sometimes just about that. He states that explaining 'a concept involves explaining the feature through which it applies to its object ..., but also explaining more broadly the nature of the object ... that it is a concept of'. ${ }^{128}$ Raz concedes that 'conceptual analysis' strictly understood does not extend this far, but he argues that legal philosophers such as Hart had in mind this 'wider sense' of 'conceptual explanations'. ${ }^{129}$ Note that conceptual analysis in this extended sense makes direct explanation of the referent itself one of its targets, rather than merely indirectly yielding insight into the referent as a by-product of its clarification of the sense of a concept-word (which, as we have seen, is a distinctive feature of all contemporary conceptual analysis).

When philosophical explanations extend this far, what distinguishes them from their social scientific counterparts is precisely the way in which they come about: philosophers' own reflection about their objects of analysis - armchair theorising, as its detractors are fond of calling it - versus the empirical methods of social scientists. We have come full circle, for the speculative character of philosophical work was just what traditional analytic philosophy objected to. So it seems that the more the analytic legal philosopher strays from raising questions about the sense, rather than the referent, of legal terms, the more problematic legal philosophy becomes.

The armchair-method critique of conceptual analysis is often overstated. Denying that conceptual analysis has, by virtue of its armchair quality, any knowledge to contribute about legal matters proceeds from faulty ontological and epistemological assumptions about such matters - from a failure to see that they do not work like natural kinds; a failure to see that we prefer to call legal things 'legal concepts' for a reason. Yet, it may be said, the critique has bite if analytic legal philosophy becomes more preoccupied with clarifying the nature of legal things than the meaning of legal concepts.

There are, however, reasons not to yield too readily to even this more targeted version of the armchair-method critique. The question of whether or not a legal philosopher is more preoccupied with

\footnotetext{
'What Are We Talking About? The Semantics and Politics of Social Kinds' (2005) 20 Hypatia 10, 12, quoted in Stoljar (n 36), 234.

${ }^{127}$ Nelson Goodman, Fact, Fiction, and Forecast (Harvard University Press 1955) 67, quoted in Donals Borchert (ed), Encyclopedia of Philosophy (2 ${ }^{\text {nd }}$ edn, MacMillan 2006) vol 8, 290. To the extent that 'reflective equilibrium' resists methodological essentialism, that is, 'the view that we can determine the general shape of our methods in advance' (Kenneth Walden, 'In Defense of Reflective Equilibrium' (2013) 166 Philosophical Studies 243, 255) the third answer is (like the second) connected to the first.

${ }^{128}$ Raz, 'Two Views on the Nature of Law' (n 4), 8.

${ }^{129}$ Raz, 'Two Views on the Nature of Law' (n 4), 8.
} 
clarifying the nature of legal things than the meaning of legal concepts will often be a fraught one. As I argued, some concepts cannot be satisfactorily clarified without turning to look at their referents. It is epistemically desirable for philosophers to pursue revisionist conceptual questions that lead them on partially a posteriori excursuses, but it is not generally practical for them to carry out these digressions through empirical study of relevant things and practices, rather than by relying on their own experientially-informed armchair reflection about them. But if we concede that it may be reasonable for philosophers to engage in such armchair reflection on the referents of their concept-words with a view to clarifying the senses of the concept-words, are we sure that we can draw a crisp line between this form of armchair theorising and armchair theorising about concept-words' referents for the sake of clarifying the nature of the referents themselves?

A more fundamental difficulty stems from the fact that, as we know, it is precisely a term's sense that determines its referent. This suggests a constitutive relationship between sense and referent which may make it both difficult and artificial to disentangle each from the other. However, as I argued above, there are reasons to believe that the discursive constitution of the referent through the sense is only partial. Therefore it is possible in principle and conceivable in at least some cases to distinguish conceptual questions ('What is judicial decision-making?') - which may require, in addition to a priori analysis of linguistic conventions, a degree of a posteriori (that is experience-based) armchair theorising about the referent - from questions about the referents of concept-words ('How do judges decide cases?'). The latter are best left to the empirical methods of the social scientist.

\section{Conclusions}

The significance of methodological questions for legal philosophy is the same as for any other discipline. It lies in the fact that the validity of the statements made within a discipline is partially contingent upon appropriate methodological choices. Clarifying its methodology is thus a crucial aspect of any mature discipline's self-understanding.

The paradigmatic case of 'conceptual analysis' aims at yielding analytic truths about the meaning of concept-words through a priori analysis, namely reflection informed by intuitions about linguistic usage. But this is something like an ideal type and since the mid-twentieth century analytic philosophers have not seen themselves as practicing the central case of conceptual analysis. Most, perhaps all, cases of conceptual analysis are such cases only by virtue of analogy to this paradigmatic case. Contemporary conceptual analysis differs from the central case because it acknowledges that the meaning of some concepts cannot be clarified in a way that makes it of interest to legal philosophers, unless the philosopher's work is partially revisionist of actual usage, and/or one relies on something other than linguistic competence to determine it especially one's experiential knowledge, one's own empirical observations, or empirical information supplied by others.

Conceptual analysis is desirable and necessary in jurisprudence because legal terms ('law') have senses that mediate between the terms and their referents (law). The concept that conceptual analysis aims to clarify is the term's sense. Because a term's sense determines the referent, clarifying concepts also provides important (albeit not necessarily irrefutable) knowledge about the world to which the concepts apply. Conceptual analysis is necessary but not sufficient to a full understanding of the nature of law and legal things. Some knowledge about law is impervious to conceptual analysis but not to empirical social science. But the reverse is also true: therefore subordinating conceptual analysis to the concerns or methods of empirical social science, as various naturalistic challenges to conceptual analysis recommend, is a mistake.

When philosophers reach beyond their linguistic competence to determine the meaning of a concept, they engage in such a posteriori moves on the basis that they assist in the clarification of the concept itself. Such a posteriori moves may or may not be from the armchair. When they are, it is not clear that too much weight should be attached to that fact. Sometimes philosophers may be less concerned with clarifying the meaning of concepts than with directly explaining, from the armchair, the nature of the thing the concept 
applies to. A revisionist conceptual account of conceptual analysis could reasonably deny that in these instances philosophers are practicing conceptual analysis, despite the fact that academic folk usage of 'conceptual analysis' may also cover these instances. If these instances are a case of conceptual analysis, it is the case in respect of which the critique of conceptual analysis on the ground that it is an armchair method has some bite.

\section{Abstract}

Conceptual analysis remains the methodology of much contemporary mainstream jurisprudence. The last fifteen years have seen significant contributions addressing the nature of conceptual analysis in legal theory, but many questions have not been answered in a satisfactory way. These questions can be more clearly addressed if we appreciate: a) that there is a central case of conceptual analysis; and b) the ways in which non-paradigmatic cases of conceptual analysis differ from the central one. Among other things, the article argues that conceptual analysis is necessary but not sufficient to a full understanding of the nature of law. Some knowledge about law is impervious to conceptual analysis but not to empirical social science. The reverse is also true. In explaining the meaning of 'conceptual analysis' the article also enacts conceptual analysis: the method the article uses to clarify the nature of conceptual analysis is precisely the method known as 'conceptual analysis'. 